\title{
A prospective cohort study of MTHFR C677T gene polymorphism and its influence on the therapeutic effect of homocysteine in stroke patients with hyperhomocysteinemia
}

\author{
Xiaoxia Du' ${ }^{1 *}$ Lin Xiao ${ }^{1}$, Rong Sun ${ }^{1}$, Kunpeng Li ${ }^{2}$, Lin Liang ${ }^{3}$, Luping Song ${ }^{1}$ and Zhizhong Liu ${ }^{3 *}$
}

\begin{abstract}
Background: Hyperhomocysteinemia (HHCY) is a risk factor for cardiovascular and cerebrovascular diseases. The C677T 5, 10-methylenetetrahydrofolate reductase (MTHFR) gene polymorphism increases homocysteine (HCY) levels. This study analyzed the relationship between C677T MTHFR polymorphism and the therapeutic effect of lowering HCY in stroke patients with HHCY.
\end{abstract}

Methods: Baseline data were collected from stroke patients with HHCY for this prospective cohort study. The C677T MTHFR genotype was detected by polymerase chain reaction-restriction fragment length polymorphism and the therapeutic effect to reduce HCY was compared.

Results: Of 200 stroke patients 162 (81.0\%) completed follow-up and were evaluated. Most of them responded well to treatment (103 cases, 63.5\%), but 59 (36.4\%) patients were in the poor efficacy group. There was a significant difference in terms of age $(P<0.001)$, hypertension $(P=0.041)$, hyperuricemia $(P=0.042)$, HCY after treatment $(P<$ $0.001)$, and MTHFR genotype $(P<0.001)$ between the poor efficacy and effective groups, with increased frequency of the $\Pi$ genotype in the poor efficacy group. Logistic regression showed that the $T$ allele was associated with poor efficacy $(\mathrm{OR}=0.733,95 \% \mathrm{Cl}$ : 0.693, 0.862, $P<0.001)$. In the codominant model the $\Pi$ genotype was associated with poor outcome $(\mathrm{OR}=0.862,95 \% \mathrm{Cl}: 0.767,0.970, P=0.017)$ and this was also the case in the recessive model $(\mathrm{OR}=0.585,95 \% \mathrm{Cl}: 0.462,0.741, P<0.001)$ but there was no association between $C T$ and $T \mathrm{~T}$ in the dominant model.

Conclusions: The T allele and T genotype of the MTHFR C677T polymorphism was associated with poor HCY reduction treatment efficacy in stroke patients with $\mathrm{HHCY}$.

(Continued on next page)

\footnotetext{
*Correspondence: 364906784@qq.com; Izzlab@126.com

'Department of Neurorehabilitation, School of Rehabilitation Medicine,

Capital Medical University, Beijing Bo'Ai Hospital, China Rehabilitation

Research Center, Beijing 100068, China

${ }^{3}$ Department of Clinical Laboratory, School of Rehabilitation Medicine, Capital

Medical University, Beijing Bo'Ai Hospital, China Rehabilitation Research

Center, Beijing 100068, China

Full list of author information is available at the end of the article
}

(c) The Author(s). 2020 Open Access This article is licensed under a Creative Commons Attribution 4.0 International License, which permits use, sharing, adaptation, distribution and reproduction in any medium or format, as long as you give appropriate credit to the original author(s) and the source, provide a link to the Creative Commons licence, and indicate if changes were made. The images or other third party material in this article are included in the article's Creative Commons licence, unless indicated otherwise in a credit line to the material. If material is not included in the article's Creative Commons licence and your intended use is not permitted by statutory regulation or exceeds the permitted use, you will need to obtain permission directly from the copyright holder. To view a copy of this licence, visit http://creativecommons.org/licenses/by/4.0/. The Creative Commons Public Domain Dedication waiver (http://creativecommons.org/publicdomain/zero/1.0/) applies to the data made available in this article, unless otherwise stated in a credit line to the data. 
(Continued from previous page)

Trial registration: The registration number of the clinical trial is ChiCTR1800020048. Registration date: December 12, 2018.

Keywords: Homocysteine, Stroke, Intracerebral hemorrhage, Methylenetetrahydrofolate reductase, Single nucleotide polymorphism

\section{Background}

The global burden of stroke is extremely high, 16.9 million people suffer a stroke each year, and the aging and increasing number of the world's population means stroke is increasing [1]. The traditional risk factors of stroke, such as hypertension, diabetes mellitus, hyperlipidemia, and atrial fibrillation have been studied extensively, and their underlying mechanisms for stroke are evident [2]. This has led to primary prevention measures that have been implemented to decrease the incidence of stroke in high income countries [1]. As stroke can lead to long-term disability, an early detection of risk factors and active control to effectively preventing the occurrence of stroke is particularly important [3]. Effective prevention is an important strategy to reduce the overall burden of stroke worldwide.

However, many other risk factors are less well understood. Homocysteine (HCY) is a less well studied nontraditional risk factor for stroke [4, 5]. Framingham's offspring cohort study found that the predictive power of the score will be improved if four biomarkers, including homocysteine, were included in the Framingham Stroke Risk Score [6, 7]. Our previous studies found that elevated $\mathrm{HCY}$ was a risk factor for stroke in young people $[8,9]$. The correlation between high HCY and stroke is stronger in younger individuals [9]. Patients with an abnormally high level of $\mathrm{HCY}$, or hyperhomocysteinemia (HHCY), are considered to be at risk of cardiovascular and cerebrovascular diseases [10-12], but its mechanism is rather complex, and not fully understood. $60.6 \%$ of stroke patients have $\mathrm{HHCY}$, which is associated with a low level of serum B12 [13]. There is indeed a significant positive correlation between $\mathrm{HCY}$ levels and ischemic stroke [14-17]. Intracerebral hemorrhage ( $\mathrm{ICH})$, which accounts for $10-15 \%$ of cases, has the highest mortality and morbidity rate among all strokes. HCY level may be an aggravating factor in atherosclerosis, which indirectly contributes to a high risk of $\mathrm{ICH}[18,19]$. High HCY concentrations may impair endothelial function, increase oxidative stress, impair methylation reactions, and alter protein structure [20]. Elevated HCY is affected by diet, nutrition, heredity, disease and drug factors [21, 22]. The contribution of genetic factors to the pathogenesis of stroke is demonstrated by the association between specific gene variants and stroke risk. However, due to conflicting results from different studies [13, 23, 24], the effects of these polymorphisms on the risk of stroke development are remain uncertain. It has been suggested that differences between studies are related to the heterogeneity of cerebral infarction [25-27].

Among genetic factors, the C677T gene polymorphism site of methylenetetrahydrofolate reductase (MTHFR) gene has become an important research locus [28]. MTHFR encodes methylenetetrahydrofolate reductase which is a rate-limiting enzyme for folic acid metabolism. Dietary folate converts to its active cofactor in $\mathrm{HCY}$ catabolism and catalyze the conversion of 5, 10methylenetetrahydrofolate to 5-methyltetrahydrofolate. Thus, it plays an important role in folic acid metabolism, DNA methylation and repair [29]. Some studies have shown that individuals with C677T MTHFR genotype have doubled HCY levels in plasma compared with normal individuals [29]. The C677T mutation apparently modifies the association between HCY and stroke [30]. However it is not clear whether the C677T MTHFR polymorphism influences efforts to decrease $\mathrm{HCY}$ in patients with stroke and HHCY.

This study aimed to compare the relationship among C677T MTHFR gene polymorphism and the risk of stroke, and the therapeutic effect of lowering HCY in stroke patients with HHCY. The results should help reduce the family burden and economic burden of the stroke through standardized prevention and treatment strategies in stroke patients with HHCY.

\section{Methods}

This prospective cohort study (ChiCTR1800020048) was approved by the institutional review board of China Rehabilitation Research Center (CRRC) (2016-018-1). Written informed consent was obtained from all the patients. The study was conducted in accordance with the principles of the Declaration of Helsinki.

\section{Patients}

From March 2016 to December 2018, we recruited stroke patients with $\mathrm{HHCY}$ in the outpatients clinic and wards of the Department of Neurorehabilitation of CRRC. The inclusion criteria were as follows: 1) age $\geq$ 18 years; 2) patients with ischemic stroke (consistent with diagnostic criteria in the 2010 guidelines for the diagnosis and treatment of acute ischemic stroke in China [31]); patients with cerebral hemorrhage 
(diagnostic criteria at the Fourth National Conference on Cerebrovascular Diseases [32]); 3) patients with $\mathrm{HHCY}(\mathrm{HCY} \geq 15 \mu \mathrm{mol} / \mathrm{L})$. The exclusion criteria were as follows: 1) patients with subarachnoid hemorrhage; patients with traumatic intracerebral hemorrhage; 2) pregnant or lactating women; 3) patients participated in or were participating in other clinical studies within 3 months; 4) patients with malignant tumors. The exit and termination criteria were: patients who could not complete the examination items as required or could not be followed up.

The clinical data of the patients were collected, including gender, age, history of hypertension, history of diabetes, history of lipid metabolism disorder, history of heart disease, and type of stroke.

\section{Detection of HCY and C677T polymorphism of the MTHFR gene}

All the subjects were tested for HCY and MTHFR C677T gene polymorphism in the Laboratory Department of CRRC.

The detection and reference values of plasma $\mathrm{HCY}$ were as follows: all patients were tested for baseline $\mathrm{HCY}$ in the morning, $5 \mathrm{ml}$ of fasting elbow venous blood was collected (heparin anticoagulation), and centrifuged for $10 \mathrm{~min}$ at $3000 \mathrm{r} / \mathrm{min}$, and the plasma HCY concentration was measured by a chemiluminescence with a BIO-RAD automatic biochemical analyzer (S1000 PCR instrument) using the mindray reagent. The normal reference range set by the kit manual was $5-15 \mu \mathrm{mol} / \mathrm{L}$ [33], and if HCY is more than $15 \mu \mathrm{mol} / \mathrm{L}, \mathrm{HHCY}$ should be considered. After 1 month of treatment, the patients were tested again.

The MTHFR C677T gene polymorphism was tested with the Baio MTHFR (C677T) gene detection kit using a BS-800 M S1000TM Thermal cycler. The C677T locus genotyping of MTHFR gene was performed by polymerase chain reaction-restriction fragment length polymorphism.

\section{Treatment}

In this study, patients were given folic acid tablets 0.4 $\mathrm{mg} /$ day, vitamin B6 100mg with 3 times/day, methylcobalamin $500 \mu \mathrm{g}$ with 3 times/day to reduce $\mathrm{HCY}$. The data of Baseline levels and HCY levels after 1 month of treatment were collected. Patients with poor efficacy were those who failed to reach the normal range or whose reduction was less than $20 \%$. The rest of the patients were considered as control groups. Patients with other diseases (hypertension, diabetes, etc.) were treated according to their original treatment plan.

\section{Statistical analysis}

SPSS 21.0 (IBM Corp., Armonk, NY, USA) statistical software was used to analyze the research data. The measurement data were expressed as ${ }^{-} \mathrm{x} \pm \mathrm{s}$. T-test was used for comparison between the two groups, and analysis of variance (ANOVA) was used for multi-group comparison. Least significant difference (LSD) test was used for pairwise comparison, and the paired t-test was used for paired data. The count data were expressed as examples (percentages) and was compared by chi-square test. Regarding effective treatment as the outcome, logistic regression was used to analyze the correlation between different genotypes and outcomes (indicators with $P<0.05$ of univariate analysis were selected for multivariate analysis). $P<0.05$ was accepted as a significant difference.

\section{Results}

Baseline characteristics and HCY change after treatment A total of 200 stroke patients were enrolled in the study. Of these, 11 cases (5.5\%) withdrew from the study due to renal insufficiency, and 27 cases (13.5\%) withdrew from the study due to hepatic insufficiency without a full course of regular treatment. A total of 162 patients $(81.0 \%)$ completed the follow-up. Most of them responded well to folic acid tablets, vitamin B6 and methlcobalamin treatment, with a reduction of more than $20 \%$ or a reduction to the normal range and so they were grouped into the effective efficacy group (103 cases, $63.5 \%)$. The remaining $59(36.4 \%)$ patients were grouped in the poor efficacy group (Table 1 ). There were significant differences between the groups in age $(P<0.001)$, hypertension $(P=0.041)$, hyperuricemia $(P=0.042)$, HCY after treatment $(P<0.001)$, and MTHFR genotype $(P<0.001)$.

\section{MTHFR polymorphism and HCY changes}

The $P$ value of the Hardy-Weinberg equilibrium test was 0.56 , which indicated the genetic balance of the population. In the poor efficacy group of 59 cases, there were 48 cases of TT, 10 cases of CT; 1 case of CC. Within this group there were 12 patients with unstable HCY levels which are increased instead of being decreased, in which 11 cases were TT, and 1 case was CT (Table 2). HCY levels before and after treatments for each genotype are shown in Table 3. These results showed that there were significant differences in HCY levels among the genotype groups before $(P=0.049)$ and after $(P=0.002)$ treatment.

Logistic regression analysis was carried out with adjustment for age, history of hypertension and hyperuricemia for the outcome of poor efficacy, and the results showed that the $\mathrm{T}$ allele was associated with poor efficacy $(\mathrm{OR}=0.733,95 \% \mathrm{CI}: 0.693,0.862, P<0.001)$. In the codominant model the TT genotype was associated with poor outcome $(\mathrm{OR}=0.862,95 \% \mathrm{CI}: 0.767,0.970, P=$ 0.017 ) and this was also the case in the recessive model $(\mathrm{OR}=0.585,95 \% \mathrm{CI}: 0.462,0.741, P<0.001)$ but there 
Table 1 Baseline characteristics and homocysteine levels before and after treatment in stroke patients grouped according to treatment efficacy

\begin{tabular}{|c|c|c|c|}
\hline & Poor efficacy group ( $n=59)$ & Effective efficacy group ( $n=103$ ) & $P$ value \\
\hline Gender, male (\%) & $51(86.4 \%)$ & $87(84.5 \%)$ & 0.734 \\
\hline Age, years & $46.51 \pm 13.7$ & $57.7 \pm 13.3$ & $<0.001$ \\
\hline \multicolumn{4}{|l|}{ Stroke types } \\
\hline Hemorrhagic, n (\%) & $34(57.6 \%)$ & $45(43.7 \%)$ & \multirow[t]{2}{*}{0.088} \\
\hline Ischemic, n (\%) & $25(42.4 \%)$ & $58(56.3 \%)$ & \\
\hline Hypertension, n (\%) & $55(93.2 \%)$ & $84(81.6 \%)$ & 0.041 \\
\hline Diabetes mellitus, n (\%) & $17(28.8 \%)$ & 38 (36.9\%) & 0.269 \\
\hline Abnormal lipid metabolism, n (\%) & $34(57.6 \%)$ & $75(72.8 \%)$ & 0.070 \\
\hline Hyperuricemia, n (\%) & $10(16.9 \%)$ & $7(6.8 \%)$ & 0.042 \\
\hline \multicolumn{4}{|l|}{$\mathrm{HCY}, \mu \mathrm{mol} / \mathrm{L}$} \\
\hline Before treatment & $26.49 \pm 15.75$ & $21.88 \pm 18.99$ & 0.116 \\
\hline After treatment & $21.64 \pm 10.81$ & $12.42 \pm 5.99$ & $<0.001$ \\
\hline \multicolumn{4}{|l|}{ MTHFR C677T genotype } \\
\hline CC, n (\%) & $1(1.7 \%)$ & $9(8.7 \%)$ & \multirow[t]{3}{*}{$<0.001$} \\
\hline $\mathrm{CT}, \mathrm{n}(\%)$ & $10(16.9 \%)$ & $45(43.7 \%)$ & \\
\hline T, n (\%) & 48 (81.4\%) & 49 (47.6\%) & \\
\hline
\end{tabular}

was no association of between $\mathrm{CT}$ and $\mathrm{TT}$ in the dominant model (Table 4).

\section{Discussion}

MTHFR involved in folate metabolism has two variants, C677T and A1298C [34]. Racial-ethnic differences in the distribution of the C677T polymorphism are welldescribed [35, 36]. Carrier rates of the $677 \mathrm{~T}$ polymorphism differ across white, Asian, and black ethnic groups. This study aimed to analyze the relationship between C677T MTHFR polymorphism and the therapeutic effect of lowering $\mathrm{HCY}$ in stroke patients with HHCY. Results from previous studies have shown that the TT genotype of the MTHFR gene in Asian countries had a greater impact on HCY levels $[15,37,38]$. The TT genotype of C677T polymorphism in the MTHFR gene contributes to the genetic susceptibility of acute ischemic stroke inpopulation of Singapore [39]. The frequency of TT genotype of MTHFR gene in this group of stroke patients was up to $57.92 \%$ (117). TT genotype is more frequently seen in Asian compared with that of white individuals, and least common in those of African ethnic origin [29], However, ethnic subgroups may in turn

Table 2 Distribution of the three MTHFR C677T genotypes in patients with poor efficacy

\begin{tabular}{llll}
\hline Patients with poor efficacy & CC $(n=1)$ & $\Pi(n=49)$ & CT $(n=9)$ \\
\hline Decrease $<20 \%(n=47)$ & 1 & 38 & 8 \\
Unstable increase $(n=12)$ & 0 & 11 & 1 \\
\hline
\end{tabular}

exhibit different carrier rates or environmental susceptibility to disease-specific morphisms, which may in part explain ethic and regional differences in stroke risk [35]. These results suggest that race and genetic factors influence the incidence of disease. The results of this study showed that overall $59.9 \%$ of the stroke patients had the TT genotype. There were no significant differences between ischemic stroke group and hemorrhagic stroke group in the comparison of TT genotype $(60.9 \%$ vs57.5\%), but the percentage of patients with the TT genotype was much higher in the poor treatment efficacy group than that of patients who achieved a good reduction in HCY levels (81.4 47.6\%). This shows the importance of early detection of $\mathrm{HCY}$ in the Chinese population with the TT genotype of MTHFR gene.

vitamin $\mathrm{B}$, especially methylcobalamin, can effectively reduce plasma $\mathrm{HCY}$. The most commonly used regimen is the combined supplementation of folic acid (vitamin B9), vitamin B12 and vitamin B6 [40]. Folic acid needs to be combined with vitamin B12 and vitamin B6 to reduce the risk of stroke effectively [41-43]. Previous studies suggested that $0.8 \mathrm{mg} / \mathrm{d}$ of folic acid have the best effect on reducing HCY [31]. The Framingham investigators and others have demonstrated reductions in total HCY following population folic acid grain fortification programs [44]. In areas where grain is not fortified, folic acid can slightly reduce stroke risk, However, there was no evidence that long-term use of larger doses of folic acid could further improve efficacy, and its safety is worthy of attention. In clinical practice, folic acid tablets, vitamin B6 and methylcobalamin are used to treat 
Table 3 Homocysteine levels before and after treatment according to MTHFR C677T genotype

\begin{tabular}{lllll}
\hline & $C C(n=10)$ & $C T(n=55)$ & $T(n=97)$ & $P$ value \\
\hline HCY before treatment, $\mu \mathrm{mol} / \mathrm{L}$ & $20.26 \pm 6.60$ & $18.90 \pm 6.37$ & $21.75 \pm 8.19$ & 0.049 \\
$\mathrm{HCY}$ after treatment, $\mu \mathrm{mol} / \mathrm{L}$ & $14.02 \pm 3.53$ & $12.98 \pm 5.01 \mathrm{ab}$ & $19.45 \pm 11.32^{\mathrm{ab}}$ & 0.002 \\
$P$ value $^{* *}$ & 0.535 & 0.328 & 0.211
\end{tabular}

*Analysis of variance was used for comparison among genotypes

${ }^{* *}$ Paired sample t-test was used for comparison between baseline and 1 month after treatment

${ }^{\mathrm{ab}}$ Different letters indicate statistical significance. Least significant difference (LSD) test was used for pairwise comparison. CCvsCT $p=0.816$; CC vs $\Pi p=0.215$; $C T$ vs $\Pi p=0.001$

HHCY. According to the US guidelines, the supplementation of three kinds of compound vitamin B could reduce $\mathrm{HCY}$ and reduce the risk of stroke in $\mathrm{HHCY}$ [41, 45]. A daily multivitamin preparations with adequate vitamin B6 and vitamin B12, and folate $(400 \mu \mathrm{g} / \mathrm{d})$ are reasonable to reduce the level of homocysteine [46]. The Chinese guidelines for Secondary Prevention of Ischemic Stroke and Transient Ischemic Attack (TIA) recommend supplementation of folic acid, vitamin B6 and vitamin $\mathrm{B} 12$ to be used to reduce $\mathrm{HCY}$ in patients with recent ischemic stroke or TIA and mild to moderate homocysteine elevation [31]. Most of the patients in this study responded well to folic acid tablets, vitamin B6 and methlcobalamin therapy. Patients affected more by genetic factors were less responsive to folic acid tablets, vitamin B6 and methlcobalamin and needed longer medication cycles. Literatures have shown that HHCY patients with TT genotype could still benefit from folic acid supplementation despite normal folic acid and vitamin B12 levels [47], but there are few studies on how to adjust treatment in a few patients with elevated levels. Elevated HCY is influenced by many factors such as diet, heredity, and drugs [48]. Further study is required to

Table 4 Logistic regression analysis of MTHFR C677T in poor efficacy cases and controls

\begin{tabular}{cllll}
\hline & Cases, $\mathrm{n}(\%)$ & Controls, $\mathrm{n}(\%)$ & OR $(95 \% \mathrm{Cl})$ & $P$ value \\
\hline Allele & & & & \\
$\mathrm{C}$ & $63(30.6)$ & $12(10.2)$ & 1.000 (referrence) & - \\
$\mathrm{T}$ & $143(69.4)$ & $106(89.8)$ & $0.773(0.693,0.862)$ & $<0.001$
\end{tabular}

Model type

\begin{tabular}{cllll}
\multicolumn{2}{c}{ Codominant } \\
CC & $9(8.7)$ & $1(1.7)$ & 1.000 (referrence) & - \\
$C T$ & $45(43.7)$ & $10(16.9)$ & $0.917(0.734,1.144)$ & 0.460 \\
$\Pi T$ & $49(47.6)$ & $48(81.4)$ & $0.862(0.767,0.970)$ & 0.017 \\
Dominant & & & & \\
$C C$ & $9(8.7)$ & $1(1.7)$ & 1.000 (referrence) & - \\
$C T+\Pi$ & $94(91.3)$ & $58(98.3)$ & $0.928(0.867,0.994)$ & 0.095 \\
Recessive & & & & \\
$C C+C T$ & $54(52.4)$ & $11(18.6)$ & 1.000 (referrence) & - \\
$\Pi T$ & $49(47.6)$ & $48(81.4)$ & $0.585(0.462,0.741)$ & $<0.001$ \\
\hline
\end{tabular}

analyze genetic subgroups within large clinical trials of HHCY therapy. Young individuals with elevated HCY and people with high blood pressure may particularly benefit from lowering HCY [49].

Several limitations of this study must be acknowledged. This study was a single-center study with a relatively small sample size and only one-month follow-up time. For HHCY patients with TT genotype, methods to controlling the abnormal increases of $\mathrm{HCY}$ (the dosage, method, type and cycle of the drugs)need to be studied, and these are our future research direction. Multi-center clinical trials using larger sample sizes and better design will be needed to validate our results.

\section{Conclusions}

In conclusion, the TT genotype of MTHFR C677T was common in this Chinese stroke population and was an independent risk factor for poor efficacy of HCY lowering treatment.

\section{Abbreviations}

HHCY: Hyperhomocysteinemia; HCY: Homocysteine; ICH: Intracerebral hemorrhage; CRRC: China Rehabilitation Research Center; MTHFR: The 5, 10methylenetetrahydrofolate reductase; OR: Odds ratio; Cl: Confidence interval; LSD: Least significant difference

\section{Acknowledgements}

The authors acknowledge the help of Basic Scientific Research Foundation of China Rehabilitation Research Center (2015zx-21, 2016zx-15, 2018zx-3).

\section{Authors' contributions}

XXD conceived and coordinated the study, designed, performed and analyzed the experiments, wrote the paper. LX, RS, KPL, LL, LPS and ZZL carried out the data collection, data analysis, and revised the paper. All authors reviewed the results and approved the final version of the manuscript.

\section{Funding}

This work was supported by Basic Scientific Research Foundation of China Rehabilitation Research Center (2015zx-21, 2016zx-15, 2018zx-3). The funder had no role in study design, data collection and analysis, decision to publish, or preparation of the manuscript.

\section{Availability of data and materials}

The datasets used and/or analyzed during the current study are available from the corresponding author on reasonable request.

\section{Ethics approval and consent to participate}

This prospective cohort study was approved by the institutional review board of CRRC (2016-018-1). Written informed consent was obtained from all the patients. The study was conducted in accordance with the principles of the Declaration of Helsinki. 


\section{Consent for publication}

Not applicable.

\section{Competing interests}

The authors declare no conflicts of interest.

\section{Author details}

'Department of Neurorehabilitation, School of Rehabilitation Medicine, Capital Medical University, Beijing Bo'Ai Hospital, China Rehabilitation Research Center, Beijing 100068, China. ${ }^{2}$ Case Statistics Office, School of Rehabilitation Medicine, Capital Medical University, Beijing Bo'Ai Hospital, China Rehabilitation Research Center, Beijing 100068, China. ${ }^{3}$ Department of Clinical Laboratory, School of Rehabilitation Medicine, Capital Medical University, Beijing Bo'Ai Hospital, China Rehabilitation Research Center, Beijing 100068, China.

\section{Received: 5 May 2019 Accepted: 26 March 2020}

\section{-}

\section{References}

1. Bejot Y, Daubail B, Giroud M. Epidemiology of stroke and transient ischemic attacks: current knowledge and perspectives. Rev Neurol. 2016;172(1):59-68.

2. Uluduz D, Ince B, Bozluolcay M. Stroke patterns, etiology, and prognosis in patients with diabetes mellitus. Neurology. 2005;64(3):581 author reply 581.

3. Uno M, Kitazato KT, Nishi K, Itabe H, Nagahiro S. Raised plasma oxidised LDL in acute cerebral infarction. J Neurol Neurosurg Psychiatry. 2003;74(3):312-6.

4. Spence JD. Homocysteine lowering for stroke prevention: Unravelling the complexity of the evidence. Int I Stroke. 2016;11(7):744-7.

5. Li J, Jiang S, Zhang Y, Tang G, Wang Y, Mao G, Li Z, Xu X, Wang B, Huo Y. $\mathrm{H}$-type hypertension and risk of stroke in chinese adults: a prospective, nested case-control study. J Transl Int Med. 2015;3(4):171-8.

6. Bostom AG, Rosenberg IH, Silbershatz H, Jacques PF, Selhub J, D'Agostino RB, Wilson PW, Wolf PA. Nonfasting plasma total homocysteine levels and stroke incidence in elderly persons: the Framingham study. Ann Intern Med. 1999;131(5):352-5.

7. Selhub J. The many facets of hyperhomocysteinemia: studies from the Framingham cohorts. J Nutr. 2006;136(6 Suppl):1726S-30S.

8. L S, CJZ L, al DXe. Comparison of etiology and risk factors between young and middle-aged and elderly patients with stroke. Chin J Med Guide. 2016; 18(1):5-6

9. Li CJ, Du XX, Yang K, Song LP, Li PK, Wang Q, Sun R, Lin XL, Lu HY, Zhang T. Effects of professional rehabilitation training on the recovery of neurological function in young stroke patients. Neural Regen Res. 2016;11(11):1766-72.

10. Hankey GJ, Eikelboom JW. Homocysteine and stroke. Lancet. 2007;365(9455): 194-6.

11. Omrani HQ, Shandiz EE, Qabai M, Chaman R, Fard HA, Qaffarpoor M. Hyperhomocysteinemia, folateo and B12 vitamin in Iranian patients with acute ischemic stroke. ARYA Atherosclerosis. 2011;7(3):97-101.

12. Parnetti L, Caso V, Santucci A, Corea F, Lanari A, Floridi A, Conte C, Bottiglieri T. Mild hyperhomocysteinemia is a risk-factor in all etiological subtypes of stroke. Neurol Sci. 2004;25(1):13-7.

13. Kalita J, Kumar G, Bansal V, Misra UK. Relationship of homocysteine with other risk factors and outcome of ischemic stroke. Clin Neurol Neurosurg. 2009;111(4):364-7.

14. Dhamija RK, Gaba P, Arora S, Kaintura A, Kumar M, Bhattacharjee J. Homocysteine and lipoprotein (a) correlation in ischemic stroke patients. J Neurol Sci. 2009:281(1-2):64-8.

15. Kawamoto R, Kohara K, Oka Y, Tomita H, Tabara Y, Miki T. An association of 5,10-methylenetetrahydrofolate reductase (MTHFR) gene polymorphism and ischemic stroke. J Stroke Cerebrovasc Dis. 2005;14(2):67-74.

16. Li Z, Sun L, Zhang H, Liao Y, Wang D, Zhao B, Zhu Z, Zhao J, Ma A, Han Y, et al. Elevated plasma homocysteine was associated with hemorrhagic and ischemic stroke, but methylenetetrahydrofolate reductase gene C677T polymorphism was a risk factor for thrombotic stroke: a multicenter casecontrol study in China. Stroke. 2003;34(9):2085-90.

17. Song Y, Li B, Wang C, Wang P, Gao X, Liu G. Association between 5,10Methylenetetrahydrofolate Reductase C677T gene polymorphism and risk of ischemic stroke: a meta-analysis. J Stroke Cerebrovasc Dis. 2016; 25(3):679-87.
18. Sato S, Uehara T, Hayakawa M, Nagatsuka K, Minematsu K, Toyoda K. Intraand extracranial atherosclerotic disease in acute spontaneous intracerebral hemorrhage. J Neurol Sci. 2013;332(1-2):116-20.

19. Zhou Z, Liang Y, Qu H, Zhao M, Guo F, Zhao C, Teng W. Plasma homocysteine concentrations and risk of intracerebral hemorrhage: a systematic review and meta-analysis. Sci Rep. 2018;8(1):2568.

20. van Guldener C, Stehouwer CD. Homocysteine and large arteries. Adv Cardiol. 2007;44:278-301.

21. Brattstrom $L$, Lindgren $A$, Israelsson $B$, Malinow MR, Norrving B, Upson $B$, Hamfelt A. Hyperhomocysteinaemia in stroke: prevalence, cause, and relationships to type of stroke and stroke risk factors. Eur I Clin Investig. 1992;22(3):214-21.

22. Verhoef $P$, Stampfer MJ, Buring JE, Gaziano JM, Allen RH, Stabler SP, Reynolds RD, Kok FJ, Hennekens CH, Willett WC. Homocysteine metabolism and risk of myocardial infarction: relation with vitamins B6, B12, and folate. Am J Epidemiol. 1996;143(9):845-59.

23. Kalita J, Srivastava R, Bansal V, Agarwal S, Misra UK. Methylenetetrahydrofolate reductase gene polymorphism in Indian stroke patients. Neurol India. 2006;54(3):260-3.

24. Kumar A, Kumar P, Prasad M, Sagar R, Yadav AK, Pandit AK, Jali VP, Pathak A. Association of C677T polymorphism in the methylenetetrahydrofolate reductase gene (MTHFR gene) with ischemic stroke: a meta-analysis. Neurol Res. 2015;37(7):568-77.

25. Banerjee I, Gupta V, Ganesh S. Association of gene polymorphism with genetic susceptibility to stroke in Asian populations: a meta-analysis. J Hum Genet. 2007;52(3):205-19.

26. Harbuzova V, Polonikov OV, Stroi DO, Matlai Ol, Ataman lu O, Sukharieva VA Ataman OV. Analysis of the effect of N5, N10-methylenetetrahydrofolate reductase gene C(677)-->T polymorphism on the ischemic stroke development in persons with various risk factors. Fiziolohichnyi zhurnal. 2014;60(2):18-24.

27. $L v Q, L u J, W u$ W, Sun $H$, Zhang J. Association of the methylenetetrahydrofolate reductase gene A1298C polymorphism with stroke risk based on a meta-analysis. Genet Mol Res. 2013:12(4):6882-94.

28. Zhu $X Y$, Hou RY, Pan $X D$, Wang YC, Zhang ZS, Guo RY. Association between the methylenetetrahydrofolate reductase (MTHFR) gene C677T polymorphism and ischemic stroke in the Chinese population: a metaanalysis. Int J Neurosci. 2015;125(12):885-94.

29. Cronin S, Furie KL, Kelly PJ. Dose-related association of MTHFR 677T allele with risk of ischemic stroke: evidence from a cumulative meta-analysis. Stroke. 2005;36(7):1581-7.

30. Zhao M, Wang X, He M, Qin X, Tang G, Huo Y, Li J, Fu J, Huang X, Cheng X, et al. Homocysteine and stroke risk: modifying effect of Methylenetetrahydrofolate Reductase C677T polymorphism and folic acid intervention. Stroke. 2017;48(5): $1183-90$.

31. The 2010 Guidelines for the diagnosis and treatment of acute ischemic stroke in China. Chinese J Clinic. 2011;39(3):227-233.

32. Wang X. Essentials for diagnosis of various cerebrovascular diseases. Chin J Neurol. 1997;3(1):3-4.

33. Bhargava S, Parakh R, Srivastava LM. Studies on homocysteine demonstrating its significance as a possible tool for differential diagnosis in occlusive vascular disease. Ind J Clin Biochem. 2004;19(1):76-8.

34. Shen $H$, Xu Y, Zheng $Y$, Qian $Y$, Yu R, Qin Y, Wang X, Spitz MR, Wei Q. Polymorphisms of 5,10-methylenetetrahydrofolate reductase and risk of gastric cancer in a Chinese population: a case-control study. Int J Cancer. 2001;95(5):332-6.

35. Schneider JA, Rees DC, Liu YT, Clegg JB. Worldwide distribution of a common methylenetetrahydrofolate reductase mutation. Am J Hum Genet. 1998:62(5):1258-60.

36. Franco RF, Araujo AG, Guerreiro JF, Elion J, Zago MA. Analysis of the 677 C-$>T$ mutation of the methylenetetrahydrofolate reductase gene in different ethnic groups. Thromb Haemost. 1998;79(1):119-21.

37. Baum L, Wong KS, Ng HK, Tomlinson B, Rainer TH, Chan DK, Thomas GN, Chen X, Poon P, Cheung WS, et al. Methylenetetrahydrofolate reductase gene A222V polymorphism and risk of ischemic stroke. Clin Chem Lab Med. 2004:42(12):1370-6.

38. Goracy I, Cyrylowski L, Kaczmarczyk M, Fabian A, Koziarska D, Goracy J, Ciechanowicz A. C677T polymorphism of the methylenetetrahydrofolate reductase gene and the risk of ischemic stroke in polish subjects. J Appl Genet. 2009:50(1):63-7. 
39. Moe KT, Woon FP, De Silva DA, Wong P, Koh TH, Kingwell B, Chin-Dusting J, Wong MC. Association of acute ischemic stroke with the MTHFR C677T polymorphism but not with NOS3 gene polymorphisms in a Singapore population. Eur J Neurol. 2008;15(12):1309-14.

40. Ubbink JB, Vermaak WJ, van der Merwe A, Becker PJ. Vitamin B-12, vitamin B-6, and folate nutritional status in men with hyperhomocysteinemia. Am J Clin Nutr. 1993;57(1):47-53.

41. Meschia JF, Bushnell C, Boden-Albala B, Braun LT, Bravata DM, Chaturvedi S, Creager MA, Eckel RH, Elkind MS, Fornage M, et al. Guidelines for the primary prevention of stroke: a statement for healthcare professionals from the American Heart Association/American Stroke Association. Stroke. 2014; 45(12):3754-832.

42. Saposnik G, Ray JG, Sheridan P, McQueen M, Lonn E. Heart outcomes prevention evaluation I: Homocysteine-lowering therapy and stroke risk, severity, and disability: additional findings from the HOPE 2 trial. Stroke. 2009:40(4):1365-72.

43. Ji Y, Tan S, Xu Y, Chandra A, Shi C, Song B, Qin J, Gao Y. Vitamin B supplementation, homocysteine levels, and the risk of cerebrovascular disease: a meta-analysis. Neurology. 2013;81 (15):1298-307.

44. Jacques PF, Selhub J, Bostom AG, Wilson PW, Rosenberg IH. The effect of folic acid fortification on plasma folate and total homocysteine concentrations. N Engl J Med. 1999;340(19):1449-54.

45. Goldstein LB, Bushnell CD, Adams RJ, Appel L, Braun LT, Chaturvedi S, Creager MA, Culebras A, Eckel RH, Hart RG, et al. Guidelines for the primary prevention of stroke: a guideline for healthcare professionals from the American Heart Association/American Stroke Association. Stroke. 2011:42(2): 517-84.

46. Sacco RL, Adams R, Albers G, Alberts MJ, Benavente O, Furie K, Goldstein LB, Gorelick P, Halperin J, Harbaugh R. Guidelines for Prevention of Stroke in Patients With Ischemic Stroke or Transient Ischemic Attack: A Statement for Healthcare Professionals From the American Heart Association/American Stroke Association Council on Stroke: Co-Sponsored by the Council on Cardiovascular Radiology and Intervention: the American Academy of Neurology affirms the value of this guideline. Stroke. 2006;37(2):577-617.

47. Kang SS, Wong PW, Bock HG, Horwitz A, Grix A. Intermediate hyperhomocysteinemia resulting from compound heterozygosity of methylenetetrahydrofolate reductase mutations. Am J Hum Genet. 1991; 48(3):546-51.

48. Cybulska B, Klosiewicz-Latoszek L. Homocysteine--is it still an important risk factor for cardiovascular disease? Kardiol Pol. 2015;73(11):1092-6.

49. Towfighi A, Markovic D, Ovbiagele B. Pronounced association of elevated serum homocysteine with stroke in subgroups of individuals: a nationwide study. J Neurol Sci. 2010;298(1-2):153-7.

\section{Publisher's Note}

Springer Nature remains neutral with regard to jurisdictional claims in published maps and institutional affiliations.

Ready to submit your research? Choose BMC and benefit from:

- fast, convenient online submission

- thorough peer review by experienced researchers in your field

- rapid publication on acceptance

- support for research data, including large and complex data types

- gold Open Access which fosters wider collaboration and increased citations

- maximum visibility for your research: over $100 \mathrm{M}$ website views per year

At BMC, research is always in progress.

Learn more biomedcentral.com/submissions 